\title{
Kereta Gantung sebagai Alternatif Wisata dan Pengurai Kemacetan Kota Wisata Batu Jawa Timur
}

\author{
Moh. Singgih P., Akhmad Yusuf Z. \\ Program Studi Diploma Teknik Sipil FTSP ITS, Surabaya \\ Email: m.singgih.purwanto@gmail.com
}

\begin{abstract}
Indonesian tourism is developing related to global economic acceleration. East java, one of the Indonesian province should be considered as tourism potencial area, Batu Municipality has an important role to attract the tourist. Especially The development in agro tourism, fresh flower, special purpose, and historical torism. Innovation is needed in developing Obyek dan Daya Tarik Wisata (ODTW). The main problem in Batu Torism is lacking main road and improper alternative road especially during weekend and holidays. Bulding of cable car is offfered as tourism innovation as well as ODTW connectivity solution in Batu. Stasion location and cable car type are determind based on environmental capacity and existing tourist traveling type in Batu
\end{abstract}

Keywords: tourism, traffic jam, connectivity, and cable car.

Abstrak

Perkembangan wisata di Indonesia semakin berkembang seiring dengan laju perekonomian dunia, Jawa Timur adalah salah satu daerah dengan potensi pariwisata yang patut diperhitungkan, Kota Batu menjadi salah satu pemeran utama dalam menarik wisatawan. Jenis wisata yang berkembang di Kota Batu meliputi wisata agro dan wisata bunga, wisata alam, wisata budaya, wisata rekreasi, wisata minat khusus, dan wisata sejarah. Dengan adanya berbagai macam jenis pariwisata, maka diperlukan inovasi dalam pengembangan Objek dan Daya Tarik Wisata (ODTW) terutama guna memenuhi kebutuhan konektifitas dan alternatif mengurangi kemacetan yang ditimbulkan ODTW tersebut, terutama pada hari libur. Liburan terjadi kemacatan karena jumlah jalan utama kurang dan jalan alternatif yang belum memenuhi kelas jalanya. Pembangunan kereta gantung sebagai moda penghubung antar ODTW adalah salahsatu opsi yang ditawarkan sebagai inovasi disektor pariwisata sekaligus solusi dalam konektifitas ODTW Kota Batu. Penentuan alternatif lokasi stasiun utama dan model kereta gantung berdasarkan hasil analisis daya dukung lingkungan dengan memperhatikan pola perjalanan wisatawan berdasarkan jalur wisata yang terjadi di Kota Wisata Batu.

Kata kunci: pariwisata, kemacetan, konektifitas, dan kereta gantung.

\section{Pendahuluan}

Perkembangan pariwisata di Indonesia semakin berkembang seiring dengan laju perekonomian dunia, Jawa Timur adalah salah satu daerah dengan potensi Pariwisata yang patut diperhitungkan. Dalam perkembangan pariwisata Jawa Timur, Kota Batu menjadi salah satu pemeran utama dalam menarik wisatawan, terutama yang berasal dari dalam negeri. Tercatat pada tahun 2013 terdapat kurang lebih 5 juta wisatawan berkunjung ke Kota Batu (BPS Kota
Batu, 2014), dimana terjadi kenaikan wisatawan sebesar 1 juta jiwa dari tahun sebelumnya yaitu sekitar 4 juta wisatawan pada tahun 2012 (BPS Kota Batu, 2014). Jenis wisata yang berkembang di Kota Batu meliputi wisata agro dan wisata bunga, wisata alam, wisata budaya, wisata rekreasi, wisata minat khusus, wisata sejarah, wisata religi, wisata ziarah, wisata husada, dan wisata kuliner. Dengan adanya berbagai macam jenis pariwisata, maka diperlukan inovasi 
dalam pengembangan Objek dan Daya Tarik Wisata (ODTW) terutama guna memenuhi kebutuhan konektifitas antar ODTW dengan tujuan mengintegrasikan satu objek wisata dengan objek wisata yang lain. Pengembangan wisata dengan meningkatkan konektifitas antar ODTW dirasa penting mengingat selalu terjadinya kemacetan lalu lintas ketika musim liburan yang disebabkan karena jumlah jalan utama dan jalan alternatif kurang, dan kelas jalannya belum memenuhi (PP No. 34, 2006). Pembangunan kereta gantung sebagai moda penghubung antar ODTW adalah salah satu opsi yang ditawarkan sebagai inovasi disektor pariwisata sekaligus solusi dalam konektifitas ODTW Kota Batu.

\section{Metodologi}

Metodologi dalam penelitian ini adalah meliputi penjabaran karakteristik kawasan wisata di seluruh kota Batu untuk kemudian dianalisis daya dukung lingkungan kawasan wisata terhadap pengembangan sarana transportasi kereta gantung untuk masing-masing zona wisata. Dari hasil analisis daya dukung lingkungan ini dapat digunakan sebagai alternatif penentuan lokasi stasiun utama dan model kereta gantung dengan mempertimbangkan pula pola perjalanan wisatawan berdasarkan preferensi rute/jalur wisata yang terjadi di kota Batu.

Kondisi karakteristik Daya Tarik Wisata (DTW) di Kota Batu, dimana data kondisi tersebut berasal dari survei primer berupa observasi dan wawancara serta kuisioner, divisualisasikan ke dalam diagram scoring berdasarkan empat komponen, yaitu daya tarik wisata, aksesibilitas, aktivitas, dan sarana dan prasarana (lihat Gambar 1). Penilaian diukur dalam empat skala dengan nilai $1,2,3$, dan 4, sesuai dengan beberapa kriteria tertentu. Kriteria scoring (lihat Tabel 1) diperoleh berdasarkan studi literatur yang telah dilakukan pada bab sebelumnya. Semakin besar nilai komponen DTW, maka semakin menunjukkan potensi lokasi wisata tersebut untuk dijadikan salah satu titik yang dilalui oleh jalur kereta gantung.

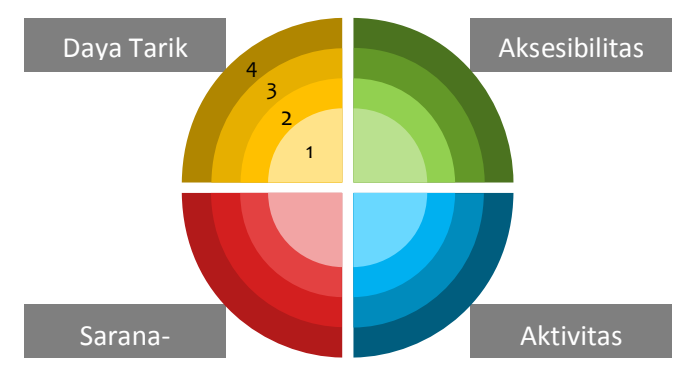

Gambar 1. Visualisasi karakteristik komponen DTW dalam Diagram Scoring (Sumber: Hasil Analisa, 2014)

\section{Hasil dan Pembahasan}

Kondisi karakteristik Daya Tarik Wisata (DTW) di Kota Batu, dimana data kondisi tersebut berasal dari survei primer berupa observasi dan wawancara serta kuisioner, divisualisasikan ke dalam diagram scoring berdasarkan empat komponen, yaitu daya tarik wisata, aksesibilitas, aktivitas, dan sarana dan prasarana. Profil ODTW berdasarkan scoring keempat komponen tersebut bisa dilihat pada Tabel 2, menunjukkan ODTW yang memiliki skor 


\section{ISSN.1907-753X}

total tertinggi sehingga berpotensi besar untuk dilalui jalur kereta gantung (lihat Tabel 2). Pada perbandingan peta pada Gambar 2, dapat terlihat bahwa ODTW dengan total skor tinggi meliputi BNS, Jatim Park II, Kusuma Agrowisata, Jatim Park I, Alun-Alun, Rafting Kaliwatu, dan
Selecta. Beberapa ODTW dengan skor tinggi cenderung terletak pada daerah selatan, tepatnya di sekitar pusat Kota Batu. ODTW paling berpotensi di daerah selatan meliputi BNS, Jatim Park II, Kusuma Agrowisata, Jatim Park I, dan Alun-Alun.

Tabel 1. Penjelasan Kriteria Scoring per Komponen

\begin{tabular}{|c|c|c|c|}
\hline No. & Komponen & Score & Penjelasan Kriteria \\
\hline \multirow[t]{4}{*}{1} & \multirow[t]{4}{*}{$\begin{array}{l}\text { Potensi daya tarik wisata } \\
\text { serta konsep/inovasi } \\
\text { terhadap daya tarik yang } \\
\text { ditawarkan }\end{array}$} & 1 & $\begin{array}{l}\text { Keunikan, keragaman, dan keindahan kurang bernilai sebagai daya } \\
\text { tarik wisata (tidak terdapat komponen something to see, something } \\
\text { to do, something to buy); Tidak terdapat eksplorasi konsep dan } \\
\text { inovasi dalam pengembangan daya tarik wisata }\end{array}$ \\
\hline & & 2 & $\begin{array}{l}\text { Keunikan, keragaman, dan keindahan cukup sebagai daya tarik } \\
\text { wisata (terdapat salah satu komponen dari something to see, } \\
\text { something to do, something to buy); Terdapat eksplorasi konsep } \\
\text { dan inovasi namun tidak terselenggara dalam pengembangan daya } \\
\text { tarik wisata }\end{array}$ \\
\hline & & 3 & $\begin{array}{l}\text { Keunikan, keragaman, dan keindahan bernilai baik sebagai daya } \\
\text { tarik wisata (terdapat dua komponen dari something to see, } \\
\text { something to do, something to buy); Terdapat eksplorasi konsep dan } \\
\text { inovasi dan terselenggara sederhana dalam pengembangan daya } \\
\text { tarik wisata }\end{array}$ \\
\hline & & 4 & $\begin{array}{l}\text { Keunikan, keragaman, dan keindahan bernilai baik sebagai daya } \\
\text { tarik wisata (terdapat seluruh komponen dari something to see, } \\
\text { something to do, something to buy); Terdapat eksplorasi konsep dan } \\
\text { inovasi dan terselenggara seluruhnya dalam pengembangan daya } \\
\text { tarik wisata }\end{array}$ \\
\hline \multirow[t]{4}{*}{2} & \multirow{4}{*}{$\begin{array}{l}\text { Jenis aktivitas yg dapat } \\
\text { dilakukan pengunjung } \\
\text { sebagai daya tarik wisata }\end{array}$} & 1 & Tidak terdapat aktivitas tertentu sebagai daya tarik wisata \\
\hline & & 2 & Terdapat sedikitnya satu jenis aktivitas sebagai daya tarik wisata \\
\hline & & 3 & Terdapat sedikitnya tiga jenis aktivitas sebagai daya tarik wisata \\
\hline & & 4 & Terdapat lebih dari tiga jenis aktivitas sebagai daya tarik wisata \\
\hline \multirow[t]{4}{*}{3} & \multirow{4}{*}{$\begin{array}{l}\text { Sarana-prasarana } \\
\text { pendukung pariwisata }\end{array}$} & 1 & Tidak terdapat jasa pariwisata \\
\hline & & 2 & Terdapat jasa pariwisata dengan jumlah dan layanan terbatas \\
\hline & & 3 & $\begin{array}{l}\text { Terdapat jasa pariwisata dengan jumlah cukup namun layanan } \\
\text { terbatas }\end{array}$ \\
\hline & & 4 & $\begin{array}{l}\text { Terdapat jasa pariwisata dengan jumlah dan layanan baik } \\
\text { (sesuai/proporsional dengan jumlah pengunjung) }\end{array}$ \\
\hline \multirow[t]{8}{*}{4} & Aksesibilitas & 1 & $\begin{array}{l}\text { Terdapat dua dari seluruh kriteria yang menunjukkan aksesibilitas } \\
\text { memadai }\end{array}$ \\
\hline & $\begin{array}{l}\text { Kriteria: } \\
\checkmark \text { perolehan informasi }\end{array}$ & 2 & $\begin{array}{l}\text { Terdapat tiga dari seluruh kriteria yang menunjukkan aksesibilitas } \\
\text { memadai }\end{array}$ \\
\hline & $\begin{array}{l}\text { mengenai tempat wisata } \\
\text { mudah didapat }\end{array}$ & 3 & $\begin{array}{l}\text { Terdapat empat dari seluruh kriteria yang menunjukkan } \\
\text { aksesibilitas memadai }\end{array}$ \\
\hline & $\begin{array}{l}\checkmark \text { tersedia peta layout } \\
\text { ODTW }\end{array}$ & 4 & $\begin{array}{l}\text { Terdapat keseluruhan kriteria yang menunjukkan aksesibilitas } \\
\text { memadai }\end{array}$ \\
\hline & $\checkmark$ waktu tempuh normal & & \\
\hline & $\checkmark$ kondisi jalan sangat baik & & \\
\hline & 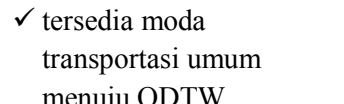 & & \\
\hline & menuju ODTW & & \\
\hline
\end{tabular}

Jurnal APLIKASI: Media Informasi \& Komunikasi Aplikasi Teknik Sipil Terkini 
Tabel 2. Skor Komponen Wisata per ODTW

\begin{tabular}{lccccc}
\hline & \multicolumn{3}{c}{ Skor Komponen } & \multirow{2}{*}{ TOTAL } \\
\cline { 2 - 5 } & DTW & Aksesibilitas & Aktivitas & Sarana-Prasarana & 15 \\
\cline { 1 - 2 } BNS & 4 & 3 & 4 & 4 & 15 \\
Jatim Park II & 4 & 3 & 4 & 4 & 16 \\
Kusuma Agrowisata & 4 & 4 & 4 & 4 & 12 \\
Pasar Besar Batu & 2 & 4 & 3 & 3 & 15 \\
Jatim Park I & 4 & 3 & 4 & 4 & 15 \\
Alun-Alun Kota Batu & 4 & 4 & 4 & 3 & 15 \\
Rafting Kaliwatu & 3 & 4 & 4 & 4 & 13 \\
Songgoriti & 2 & 4 & 3 & 4 & 12 \\
Desa Petik Bunga & 4 & 2 & 3 & 3 & 14 \\
Paralayang Gn.Banyak & 4 & 3 & 4 & 3 & 15 \\
Desa Kungkuk & 3 & 1 & 2 & 2 & 11 \\
Selecta & 4 & 3 & 4 & 4 & 9 \\
Air Terjun Coban Talun & 2 & 4 & 2 & 3 & \\
Desa Apel & 2 & 3 & 2 & 2 & 15 \\
\hline
\end{tabular}

Sumber: Hasil Analisa, 2014

Sementara itu pada daerah utara atau yang letaknya menjauh dari pusat kota, ODTW yang berpotensi besar meliputi Slecta, Rafting Kaliwatu, Paralayang Gunung Banyak, dan Songgoriti. Kusuma Agrokusuma memiliki skor total paling tinggi diantara ODTW lainnya. Berdasarkan skor di masing-masing komponen, Kusuma Agrowisata memiliki skor paling unggul pada komponen aksesibilitas. Satu komponen inilah yang membuat ODTW ini memiliki skor sempurna diantara ODTW lainnya.

BNS, Jatim Park I, dan Jatim Park II memiliki kelemahan pada komponen aksesibilitasnya. Sesuai dengan kajian profil pada pembahasan sebelumnya, ketiga ODTW ini memiliki masalah pada keterjangkauan dari segi waktu tempuh perjalanannya. Kondisi ODTW yang cenderung memberi tarikan pergerakan yang cukup besar, kedekatan lokasi dengan pusat kota, dan prasarana jalan di Kota Batu yang relatif sempit berdampak pada kemacetan. Masalah kemacetan ini terjadi mulai dari jalan masuk ke Kota Batu hingga jalan yang mengarah pada ketiga ODTW tersebut.

ODTW lain di daerah selatan yang cukup berpotensi adalah Alun-Alun Kota Batu. Ketiga komponen wisata di ODTW ini berada pada skor sempurna, kecuali pada komponen sarana dan prasarana. Kondisi ODTW yang selalu dipadati pengunjung dan posisi lokasi yang berada di pusat kota, membuat Alun-Alun berketerbatasan dalam penyediaan lahan parkir pengunjung. Keterbatasan lahan parkir inilah yang menjadi kelemahan Alun-Alun Kota Batu dalam penilaian ODTW potensial yang dapat dilalui jalur kereta gantung.

Sementara itu di daerah utara, ODTW dengan skor tertinggi dan setara dengan empat skor terbesar di daerah selatan adalah Selecta dan Rafting Kaliwatu. Komponen yang menjadi kelemahan dari Selecta adalah pada segi aksesibilitasnya. Berbeda dengan ODTW milik Jatim Park Group, kendala aksesibilitas di Selecta ini adalah pada kondisi jalan yang kurang baik.

Halaman 24 Jurnal APLIKASI: Media Informasi \& Komunikasi Aplikasi Teknik Sipil Terkini 


\section{ISSN.1907-753X}

Selebihnya, komponen wisata lain pada ODTW ini sudah cukup baik. Sementara itu, Rafting Kaliwatu memiliki kelemahan pada komponen Daya Tarik Wisatanya. Eksplorasi dan inovasi daya tarik wisata yang ditawarkan di ODTW ini masih terselenggara secara sederhana sehingga kurang mencapai skor tinggi dari daya tarik wisata.

ODTW lain yang juga berpotensi di daerah utara adalah Paralayang Gunung Banyak. Daya tarik wisata di lokasi sangat berpotensi karena memiliki panorama alam yang sangat bagus. Namun demikian kelemahan dari ODTW ini adalah dari segi aksesibilitasnya karena jalan menuju lokasi ini banyak yang berlubang. Sementara itu ODTW lain yang cukup berpotensi di daerah utara seperti Songgoriti, Desa Petik Bunga, Air Terjun Coban Talun, Desa Petik Apel, dan Desa Kungkuk memerlukan perhatian khusus dari pemerintah pada komponen Daya Tarik Wisata, Aksesibilitas, Aktivitas, dan Sarana Prasarana, agar mampu setara dengan kondisi ODTW di daerah selatan.
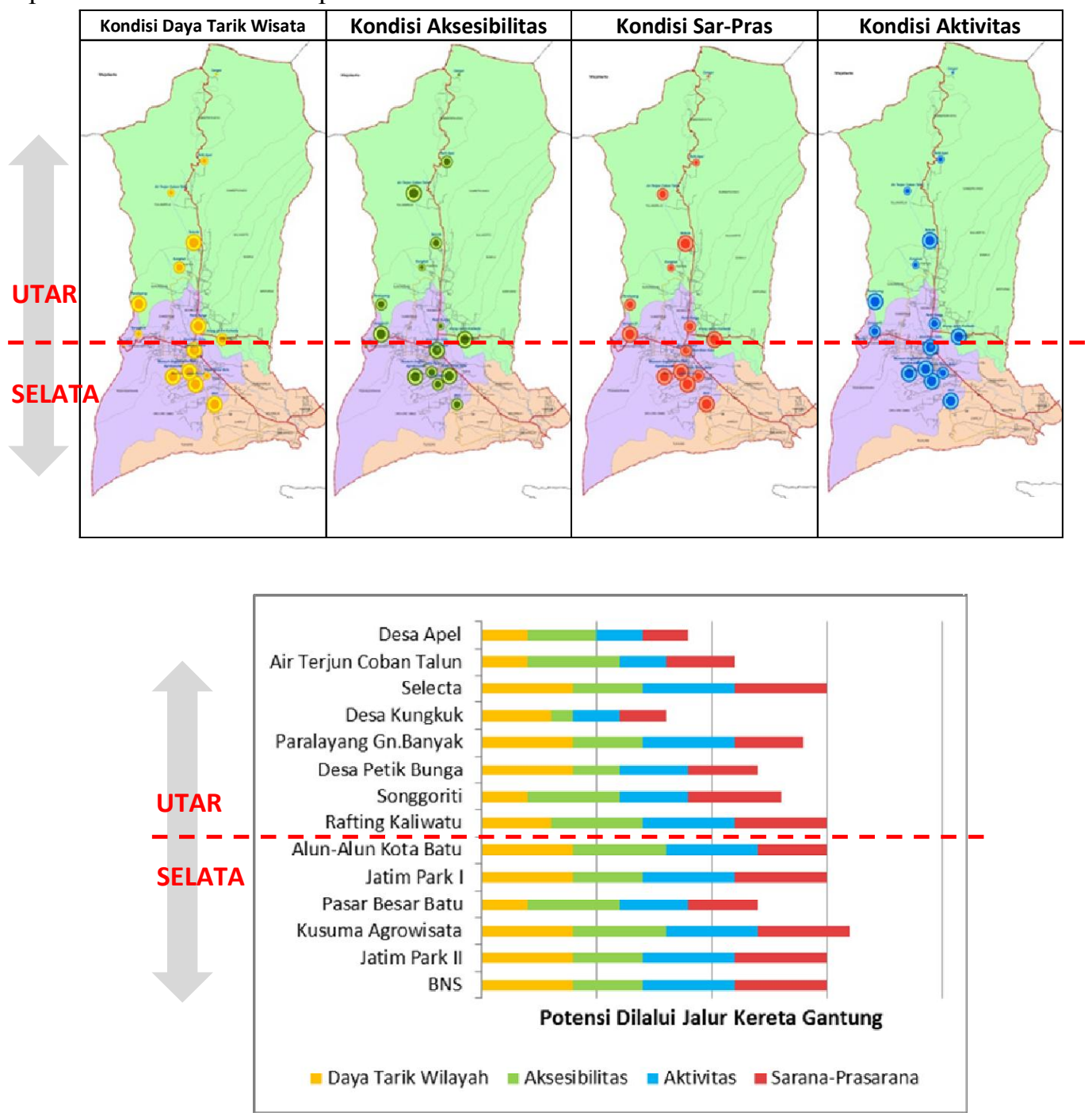

Gambar 2. Potensi ODTW Daerah Utara-Selatan (Sumber: Hasil Analisa, 2014) 
Mempertimbangkan dari kondisi potensi ODTW di atas, rekomendasi jalur kereta gantung disesuaikan dengan kelebihan dan kelemahan dari masing-masing ODTW. Secara umum kondisi ODTW di daerah selatan terkendala oleh padatnya kegiatan dan pergerakan di pusat kota meski memiliki kekuatan daya tarik wisata yang cukup besar. Sementara ODTW yang berada di daerah utara umumnya masih lemah pada keempat komponen wisata tersebut meski memiliki keunikan daya tarik alam yang tidak dimiliki oleh mayoritas ODTW di daerah selatan. Untuk itu, jalur kereta gantung sebaiknya dibagi menjadi dua yaitu South Line dan North Line.South Line bertujuan untuk memecah kepadatan lalu lintas di pusat kota yang diakibatkan oleh tarikan ODTW di daerah selatan. Sedangkan North Line bertujuan untuk meningkatkan potensi wisata pada ODTW di daerah utara.

\section{Simpulan}

Alternatif 1 rute kereta gantung dimulai dengan penempatan stasiun utama pada daerah selatan wilayah Kota Batu tepatnya pada perencanaan wisata Asean Culture Park. Daerah perencanaan Asean Culture Park merupakan pintu masuk awal yang merupakan akses utama wisatawan menuju Kota Batu. Pemilihan letak stasiun utama pada titik ini bertujuan untuk meminimalisir frekuensi kendaraan wisatawan yang akan masuk menuju pusat Kota Batu.

Secara konseptual, pemilihan rute kereta gantung dibagi menjadi dua wilayah yaitu South Line (wilayah selatan) dan North Line (wilayah utara). Pembagian rute wilayah kereta gantung ini dikarenakan adanya fungsi yang berbeda dari masingmasing rute. South Line bertujuan untuk mengurai kemacetan dengan menghubungkan ODTW yang memiliki karakteristik tarikan pergerakan wisatawan tinggi. North line bertujuan untuk mengoptimalkan potensi ODTW kota batu bagian utara yang saat ini masih belum populer (Gambar 3). Selain itu wilayah Batu bagian utara dirasa tepat sebagai wilayah yang dilalui kereta gantung karena adanya potensi panorama alam.

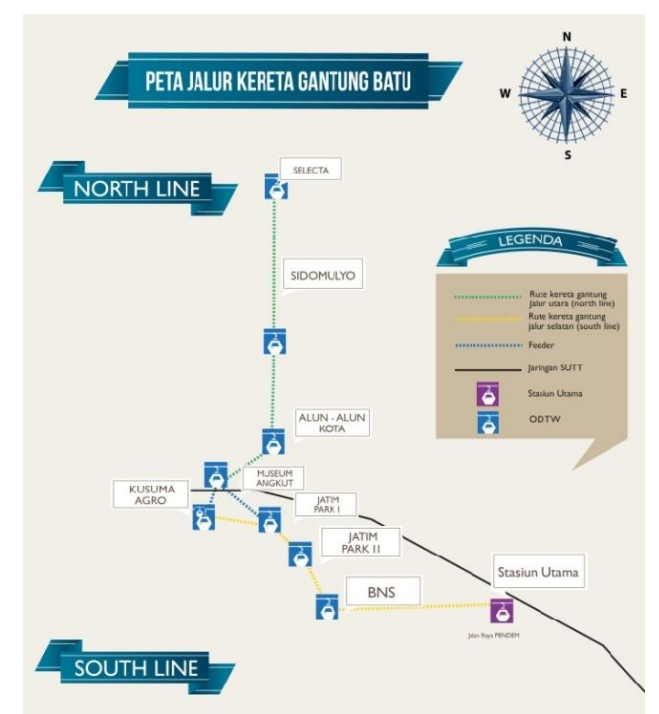

Gambar 3. Rute Alternatif 1 (Sumber:

Hasil Analisa, 2014)

Alternatif 2 rute kereta gantung dimulai dengan penempatan stasiun utama pada daerah utara wilayah Kota Batu tepatnya pada wilayah sekitar ODTW arum jeram Kaliwatu. Pemilihan letak stasiun utama pada titik ini bertujuan untuk memecah arus lalu lintas kendaraan wisatawan yang akan masuk menuju pusat Kota Batu. Secara umum wisatawan masuk Kota Batu melalui wilayah selatan. Dengan adanya stasiun utama kereta gantung di wilayah utara, wisatawan tidak perlu melalui wilayah selatan untuk menuju ODTW diseluruh Kota Batu. Perencanaan stasiun utama kereta gantung di wilayah

Halaman 26 Jurnal APLIKASI: Media Informasi \& Komunikasi Aplikasi Teknik Sipil Terkini 


\section{ISSN.1907-753X}

utara mengakomodasi tempat parkir kendaraan wisatawan. Sehingga, dalam proses berwisata, wisatawan dapat menggunakan moda kereta gantung untuk mengakses seluruh ODTW yang ada di Kota Batu (Gambar 4).

Secara konseptual umum, rute alternatif 2 memiliki tujuan yang hampir sama dengan perencanaan rute alternatif 1 , yaitu pemecah arus pergerakan wisatawan dan peningkatan potensi wisata dengan membagi wilayah rute kereta gantung menjadi South Line dan North Line.

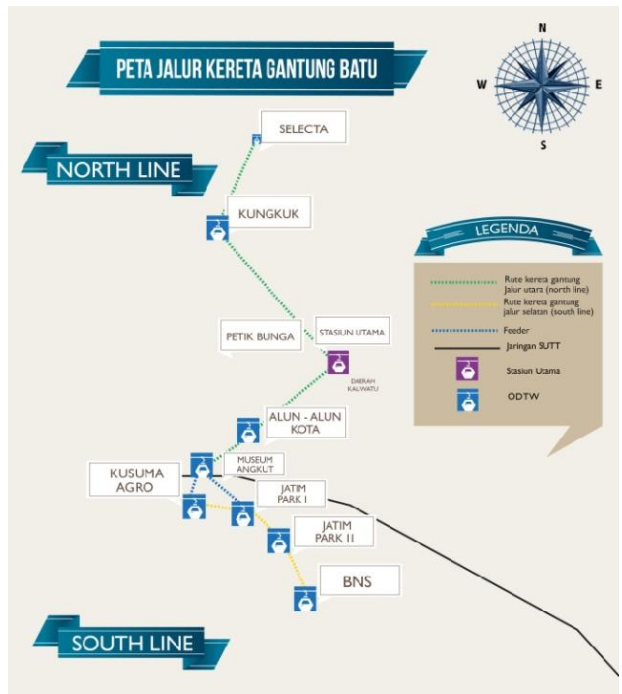

Gambar 4. Rute Alternatif 2 (Sumber: Hasil Analisa, 2014)

Adapun perbedaan konsep dari alternatif 1 dan 2 adalah konsep alternatif 2 lebih cenderung mengeksplorasi wilayah Kota Batu bagian utara. Tujuan eksplorasi ini agar kecenderungan kegiatan berwisata wisatawan tidak berpusat pada ODTW pusat kota. Di sisi lain, fungsi kereta gantung selain sebagai sarana transportasi adalah sebagai moda untuk menjangkau wilayah-wilayah yang sulit terakses melalui darat. Wilayah Batu bagian selatan memiliki daerah dengan potensi panorama yang hanya dapat diakses melalui udara (kereta gantung).

\section{Daftar Pustaka}

BPS, Kota Batu. "Kota Batu Dalam Angka tahun 2013". Juni 2014.

http://batukota.bps.go.id/batuweb/w ebsite/flipping_publikasi/Kota-

Batu-Dalam-Angka2013/indexFlip.php

BPS, Kota Batu. "Kota Batu Dalam Angka tahun 2014". Juni 2014. http://batukota.bps.go.id/batuweb/w ebsite/flipping_publikasi/Kota-

Batu-Dalam-Angka2014/indexFlip.php

Peraturan Pemerintah Republik Indonesia No.34 Tahun 2006 ,Jalan. 
